\title{
Pengaruh Metode Plasma dalam Peningkatan Penyerapan Minyak Kayu Manis (Cinnamon oil) pada Kaos Kaki dan Uji Aktivitas Antibakterinya terhadap Staphylococcus epidermidis Penyebab Bau Kaki
}

\author{
Yosi Siti Solihah* \\ Prodi Farmasi, Fakultas Matematika dan Ilmu Pengetahuan Alam, \\ Universitas Islam Bandung, Indonesia. \\ *yosisiti09@gmail.com
}

\begin{abstract}
This research aims to determine of the effect of plasma corona discharge method on the surface on socks made of Chief Value Cotton which is then soaked in cinnamon oil. This study also compare the differences between socks using and without using plasma method. After being given the treatment, the sample are testing for evaluation including physical evaluation using SEM (Scanning Electron Microscope) to see the morphological differences of the surface CVC fabric microscopically after being given plasma treatment and without plasma treatment. Chemical evaluation was carry out using FTIR (Fourier Transform Infrared) to identify the chemical groups contained in the CVC fabric after cinnamon oil was implanted in plasma treated and non plasma treated fabric. Furthermore, evaluation of antibacterial activity was carry out to compare the inhibition zones on the fabric with plasma treatment and without plasma treatment. Finally the stability test was carried out by washing the sample for twelve washes. Where in the 6th and 12th washing are testing the antibacterial activity of the sample of Staphylococcus epidermidis. From the results of research and evaluation, shown that the plasma method is a more effective technique than just immersion process.
\end{abstract}

Keywords: foot odor, plasma, cinnamon oil, Staphylococcus epidermidis.

Abstrak. Penelitian ini bertujuan untuk mengetahui pengaruh metode plasma pijar korona pada permukaan kaos kaki berbahan Chief Value Cotton yang selanjutnya dilakukan perendaman terhadap minyak kayu manis (Cinnamon oil). Pada penelitian ini juga membandingkan perbedaan dari kaos kaki yang menggunakan dan tanpa menggunakan metode plasma. Setelah diberi perlakuan tersebut, sampel dilakukan uji evaluasi meliputi evaluasi fisik dengan menggunakan alat SEM (Scanning Electron Microscope) guna melihat perbedaan morfologi dari permukaan kain CVC secara mikroskopis setelah diberikan perlakuan plasma dan tanpa perlakuan plasma. Evaluasi kimia dilakukan dengan menggunakan FTIR (Fourier Transform Infrared) guna mengidentifikasi gugus kimia yang terdapat pada kain CVC setelah ditanamkan minyak kayu manis baik pada kain dengan perlakuan plasma dan yang tidak diberi perlakuan plasma. Selanjutnya dilakukan evaluasi antibakteri guna membandingkan diameter zona hambat pada kain dengan perlakuan plasma dan tanpa perlakuan plasma. Terakhir, dilakukan uji stabilitas dengan mencuci sampel sebanyak dua belas kali pencucian. Dimana pada pencucian ke-6 dan ke-12 dilihat aktivitas antibakteri sampel terhadap Staphylococcus epidermidis. Dari hasil penelitian dan evaluasi yang dilakukan menunjukkan bahwa metode plasma merupakan teknik yang lebih efektif dibandingkan hanya dilakukan proses perendaman saja.

Kata Kunci: Bau kaki, plasma, minyak kayu manis, Staphylococcus epidermidis. 


\section{A. Pendahuluan}

Setiap orang memiliki berbagai macam aktivitas baik ringan maupun berat yang dapat memicu sekresi keringat pada tubuh. Sekresi keringat merupakan metabolisme yang normal. Namun rutinitas yang padat pada sebagian orang menyebabkan produksi keringat ketika beraktifitas menjadi lebih banyak. Pengeluaran keringat dalam frekuensi yang banyak dapat berdampak pada mekanisme penguapan keringat (Tiran, 2014).

Salah satu bagian tubuh yang banyak memproduksi keringat adalah kaki. Kaki yang sering tertutup akan kekurangan sirkulasi sehingga menimbulkan panas dan produksi keringat pada kaki akan meningkat. Hal ini menjadi salah satu faktor timbulnya masalah kepercayaan diri yaitu bau kaki (bromodosis). Bau kaki dapat merangsang penyakit kesehatan lain seperti jamur pada kaki. Timbulnya bau kaki disebabkan akibat keringat yang bercampur dengan bakteri. Beberapa bakteri penyebab bau kaki antara lain adalah Staphylococcus epidermidis, Pseudomonas aeruginosa, Staphylococcus aureus, dan Streptococcus pyogenesis (Kobayashi,1990).

Namun diketahui bahwa kebanyakan bakteri pada kaki adalah Staphylococcus epidermidis. Staphylococcus epidermidis ini dapat mendegradasi leusin yang diproduksi oleh keringat menjadi asam isovalerat, yaitu asam lemak yang menyebabkan bau pada kaki (Ara dkk, 2006). Upaya dalam menangani bau pada kaki dapat diatasi dengan sediaan yang mengandung bahan sebagai anti bakteri dan penghilang bau.

Upaya dalam menangani bau pada kaki dapat diatasi dengan sediaan yang mengandung bahan sebagai anti bakteri dan penghilang bau. Kayu manis (Cinnamomum burmannii) merupakan salah satu bahan alam yang memiliki kandungan senyawa kimia seperti sinamaldehid (60,72\%), eugenol $(17,62 \%)$ dan kumarin $(13,39 \%)$ (Guenther, 2006). Sinamaldehid dan eugenol memiliki khasiat sebagai antibakteri (Yuliarto, 2012). Minyak kayu manis (cinnamon oil) diketahui dapat menghambat pertumbuhan dari Staphylococcus epidermidis (Gupta, Garg, Uniyal, dan Kumari, 2008).

Sediaan atau produk antibau kaki yang sudah beredar saat ini diantaranya terdapat sediaan sabun antibakteri, serbuk sebagai bahan yang dapat digunakan untuk merendam kaki, anti prespirant, dan krim. Dalam hal ini tekstil juga dapat dikembangkan sebagai media atau alat untuk mempermudah, mengendalikan serta mengobati suatu penyakit dengan prosedur tertentu. Tekstil yang digunakan di bidang medis disebut sebagai Medical Textile (Mutia, 2009).

Pada proses tekstil medis, teknologi plasma dapat digunakan untuk meningkatkan sifat hidrofilik dan adhesi, meningkatkan pewarnaan, menanamkan sifat hidrofobik, serta kefungsian bahan tekstil seperti anti-bakteri, anti UV serta fungsi medis lainnya yang bergantung pada proses plasma (Mutia, 2009). Teknologi plasma juga mampu memodifikasi permukaan kain serta mampu memproses material menjadi berukuran nanometer sehingga memiliki kemampuan dalam menjerap suatu bahan (Achmad, 2015).

Plasma sendiri merupakan substansi yang mirip gas dengan bagian tertentu dan partikel yang terionisasi (Amril, 2015). Plasma terdiri dari ion, elektron bebas, radikal bebas, reaksi kimia, pembentukan senyawa siklik, perusakan molekul secara sempurna yang dapat bermanfaat untuk proses penyempurnaan tekstil terutama pada permukaan kain tanpa merusak struktur dalam serat ataupun bahan kain (Achmad, 2015).

Kenyamanan dalam penggunaan sediaan tentunya perlu diperhatikan, sehingga minyak kayu manis (cinnamon oil) untuk mengatasi bau kaki ditanamkan kedalam tekstil berupa kaos kaki dengan bantuan teknologi plasma yang diharapkan mampu meningkatkan efektivitas penjerapan minyak kayu manis tersebut pada tekstil kaos 
kaki.

Berdasarkan latar belakang tersebut dapat dirumuskan permasalahan yaitu bagaimana metode yang lebih efektif untuk menjerap minyak kayu manis (cinnamon oil) pada tekstil berupa kaos kaki yang dilihat dari uji evaluasi fisika, uji evaluasi kimia, uji aktivitas antibakteri dan uji stabilitas dari kaos kaki mengandung minyak kayu manis.

Dengan demikian tujuan dari penelitian yang dilakukan adalah untuk memperoleh metode yang lebih efektif dalam menjerap minyak kayu manis pada tekstil kaos kaki sehingga memiliki aktivitas antibakteri terhadap Staphylococcus epidermidis sebagai penyebab bau pada kaki. Hasil dari penelitian ini diharapkan dapat memperoleh informasi bahwa tekstil dapat diaplikasikan sebagai terapi dalam mengatasi bau pada kaki.

\section{B. Metodologi Penelitian}

Penelitian ini dilakukan beberapa tahap dimulai dengan penyiapan minyak atsiri kayu manis (cinnamon oil) yang diperoleh dari Lansida group, kecamatan kotagede, kota yogyakarta. Kemudian bahan tekstil yang digunakan pada penelitian ini merupakan kaos kaki berbahan cve (chief value cotton) dimana bahan cvc ini merupakan campuran antara bahan polyester dan cotton yang diperoleh dari Jakarta Utara. Tahap pertama dilakukan uji aktivitas dari berbagai konsentrasi terhadap bakteri staphylococcus epidermidis dengan metode difusi agar. Dari hasil pengujian kemudian ditentukan nilai konsentrasi dari minyak kayu manis yang akan menjadi dasar untuk selanjutnya digunakan dalam penanaman minyak kayu manis kedalam bahan tekstil medis berupa kaos kaki.

Selanjutnya minyak kayu manis yang telah ditentukan konsentrasinya ditanamkan kedalam bahan tekstil kaos kaki CVC dengan dua perlakuan, yaitu perendaman dan perlakuan plasma perendaman. Kemudian dilakukan evaluasi terhadap sediaan akhir tekstil medis meliputi evaluasi fisik menggunakan sem, evaluasi kimia menggunakan ftir dan evaluasi farmakologi dengan pengujian aktivitas antibakteri serta dibandingkan dengan produk pasaran. Kemudian dilakukan juga evaluasi stabilitas terhadap sediaan tekstil medis berupa kaos kaki dengan mencuci sampel uji tersebut sebanyak dua belas kali, dimana pada pencucian ke-6 dan ke-12 kali dilakukan uji aktivitas antibakteri kembali. Hasil yang diperoleh dibuat sebagai laporan akhir.

\section{Hasil Penelitian dan Pembahasan}

Uji aktivitas antibakteri minyak kayu manis

Pada penelitian ini dilakukan uji aktivitas antibakteri terhadap Staphylococcus epidermidis yang diketahui dapat menyebabkan bau kaki agar dapat memastikan bahwa minyak kayu manis (cinnamon oil) yang akan ditanamkan dalam kaos kaki memiliki kemampuan dalam menghambat pertumbuhan Staphylococcus epidermidis tersebut.

Uji aktivitas antibakteri minyak kayu manis ini juga dilakukan untuk menentukan konsentrasi minyak kayu manis yang dapat dipertimbangkan dalam formulasi kaos kaki mengandung minyak kayu manis (cinnamon oil). Pada penelitian ini digunakan Staphylococcus epidermidis ATCC 12228 sebagai bakteri uji.

Tabel 1. Uji aktivitas antibakteri minyak kayu manis

\begin{tabular}{|c|c|c|c|}
\hline Sampel & Konsentrasi & Diameter zona hambat (mm) & Keterangan \\
\hline \multirow{3}{*}{$\begin{array}{l}\text { Minyak kayu manis } \\
\text { (cinnamon oil) }\end{array}$} & $20 \%$ & 42,80 & Aktif \\
\hline & $15 \%$ & 37,60 & Aktif \\
\hline & $10 \%$ & 33,50 & Aktif \\
\hline Amoxicillin & $10 \mathrm{ppm}$ & 17,10 & Aktif \\
\hline Etanol & $96 \%$ & 6,00 & Tidak aktif \\
\hline
\end{tabular}


Berdasarkan hasil uji mengenai aktivitas minyak kayu manis (cinnamon oil) terhadap Staphylococcus epidermidis yang dilakukan pada konsentrasi 10, 15 dan $20 \%$ berhasil menghambat pertumbuhan bakteri tersebut. Hasil uji menyatakan bahwa konsentrasi sampel yang menghambat pertumbuhan bakteri paling besar yaitu pada konsentrasi $20 \%$. Hal ini dapat menjadi landasan yang membuktikan bahwa pada konsentrasi $10 \%$ minyak kayu manis (cinnamon oil) sudah dapat menghambat pertumbuhan Staphylococcus epidermidis dengan kategori sangat kuat atau sangat aktif.

\section{Perlakuan terhadap tekstil kaos kaki}

Pada penelitian ini dilakukan dua perlakuan yaitu perendaman kain CVC kedalam minyak kayu manis (cinnamon oil) dan perlakuan plasma terhadap kain CVC yang kemudian dilakukan perendaman kedalam minyak kayu manis (cinnamon oil). Untuk proses perendaman, minyak kayu manis yang digunakan yaitu sebesar $10 \%$ berdasarkan hasil uji aktivitas antibakteri yang telah dilakukan. Menurut Amelia (2015:3) dalam hal ini perendaman dengan minyak kayu manis sebagai zat aktif pada tekstil kaos kaki bertujuan agar tekstil tersebut mempunyai efektivitas sebagai antibakteri.

Sedangkan untuk perlakuan plasma terhadap kain CVC sebelumnya dilakukan variasi waktu treatment plasma dan jarak dari ujung elektroda menuju ke sampel kain. Metode plasma yang digunakan adalah jenis metode plasma non-termal dengan teknik plasma lucutan pijar korona. Treatment plasma ini menjadikan permukaan material kain menjadi kasar dan berpori dengan skala mikrometer atau bahkan nanometer serta dapat menanamkan sifat adhesi dan hidrofilik. Dibuat variasi jarak dan waktu berdasarkan lamanya waktu serap untuk mengetahui jarak optimal yang akan digunakan pada penelitian. Adapun variasi waktu dan jarak yang diperoleh adalah sebagai berikut:

Tabel 2. Hasil variasi waktu

\begin{tabular}{|c|c|c|c|c|c|c|c|c|c|c|}
\hline \multirow{2}{*}{ No } & \multirow{2}{*}{$\begin{array}{l}\text { Waktu Plasma (menit) } \\
\text { dengan jarak } 4 \mathrm{~cm}\end{array}$} & \multicolumn{6}{|c|}{ Lama waktu serap (menit) } & \multicolumn{2}{|c|}{ Massa (gram) } & \multirow{2}{*}{ Sudut kontak } \\
\hline & & $\mathrm{X1}$ & $\mathrm{X} 2$ & $\mathbf{X 3}$ & $\mathrm{X4}$ & $\mathrm{X5}$ & $\bar{X}$ & Sebelum & Sesudah & \\
\hline 1 & 1 & 1,07 & 1,07 & 1,08 & 1,06 & 1,06 & 1,068 & 1,639 & 1,62 & $65,3^{\circ}$ \\
\hline 2 & 2 & 1,06 & 1,05 & 1,05 & 1,03 & 1,04 & 1,046 & 1,608 & 1,59 & $62,7^{\circ}$ \\
\hline 3 & 3 & 0,5 & 0,51 & 0,5 & 0,52 & 0,53 & 0,512 & 1,633 & 1,61 & $58,9^{\circ}$ \\
\hline 4 & 4 & 0,49 & 0,5 & 0,5 & 0,49 & 0,48 & 0,492 & 1,602 & 1,59 & $54,1^{\circ}$ \\
\hline
\end{tabular}

Tabel 3. Hasil variasi jarak

\begin{tabular}{|c|c|c|c|c|c|c|c|c|c|c|}
\hline \multirow{2}{*}{ No } & \multirow{2}{*}{$\begin{array}{c}\text { Jarak }(\mathrm{cm}) \text { dengan } \\
\text { waktu } 4 \text { menit }\end{array}$} & \multicolumn{6}{|c|}{ Lama waktu serap (menit) } & \multicolumn{2}{|c|}{ Massa (gram) } & \multirow{2}{*}{ Sudut kontak } \\
\hline & & $\mathrm{X} 1$ & $\mathrm{X} 2$ & $\mathbf{X 3}$ & $\mathrm{X} 4$ & $\mathrm{X5}$ & $\bar{X}$ & Sebelum & Sesudah & \\
\hline 1 & 4 & 0,44 & 0,46 & 0,47 & 0,47 & 0,49 & 0,466 & 1,559 & 1,54 & $49,5^{\circ}$ \\
\hline 2 & 4,5 & 1 & 1,02 & 1 & 0,59 & 1,02 & 0,926 & 1,568 & 1,55 & $52,7^{\circ}$ \\
\hline 3 & 5 & 1,04 & 1,03 & 1,03 & 1,04 & 1,05 & 1,038 & 1,556 & 1,54 & $65,5^{\circ}$ \\
\hline 4 & 5,5 & 1,07 & 1,08 & 1,05 & 1,08 & 1,03 & 1,062 & 1,588 & 1,56 & $70,5^{\circ}$ \\
\hline
\end{tabular}

Dari variasi yang dibuat, jarak dan waktu yang digunakan adalah pada waktu 4 menit dengan jarak $4 \mathrm{~cm}$. Hal ini didasarkan pada penyerapan yang paling banyak dengan waktu yang paling sebentar. Menurut Putra dan Andrian (2019) terjadinya penyerapan yang lebih cepat pada material yang dikenai plasma dapat disebabkan oleh perubahan sudut kontak dan energi permukaan substrat yang terpengaruh oleh perlakuan modifikasi permukaan plasma. Semakin kecil nilai sudut kontak $\theta \leq 90^{\circ}$ menunjukkan derajat pembasahan yang semakin besar. 


\section{Uji Evaluasi Tekstil Medis \\ Evaluasi fisika}

Uji fisika dalam hal ini dilakukan menggunakan alat SEM (Scanning Electron Microscope) untuk melihat perbedaan morfologi dari permukaan kain secara mikroskopis antara kain CVC setelah diberikan perlakuan perendaman terhadap minyak kayu manis (cinnamon oil) dan kain CVC setelah diberikan perlakuan plasma yang dilanjutkan dengan perendaman terhadap minyak kayu manis (cinnamon oil).

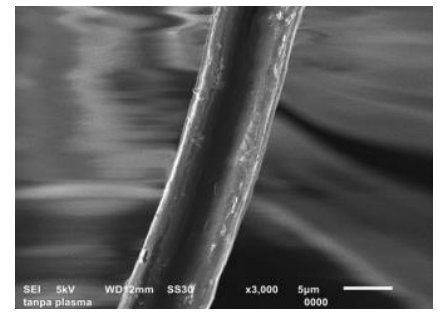

(a)

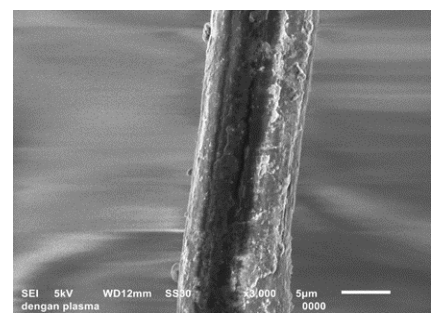

(c)

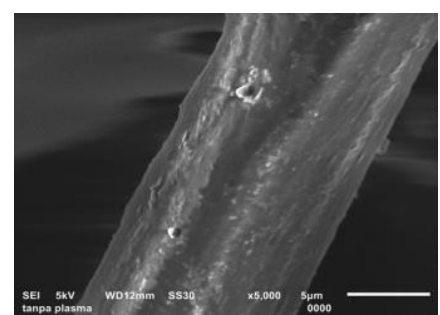

(b)

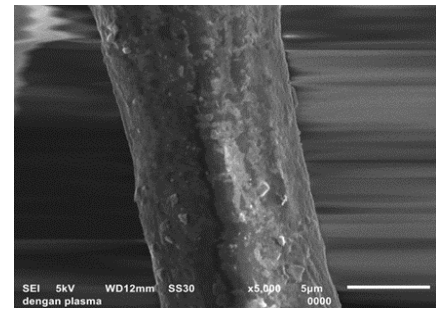

(d)

Gambar 1. (a) (b) tanpa perlakuan plasma; (c) (d) dengan perlakuan plasma

Gambar 1 (a) dan (b) menunjukkan permukaan pada kain CVC yang tidak diberi perlakuan plasma tidak menunjukkan indikasi terjadinya kerusakan atau kekasaran pada permukaan serat. Dimana kain CVC tanpa perlakuan plasma memiliki permukaan yang relatif rata. Pada permukaan kain CVC yang tidak diberi perlakuan plasma terlihat minyak kayu manis (cinnamon oil) yang menempel pada permukaan kain CVC karena adanya proses perendaman. Hal tersebut terjadi karena proses migrasi minyak kayu manis (cinnamon oil) yang bergerak menempel pada kain yang kemudian terjadi proses absorpsi sehingga minyak kayu manis (cinnamon oil) akan terserap dan menempel pada kain CVC. Hal ini juga dipengaruhi oleh proses difusi dimana proses ini merupakan proses penyerapan minyak kayu manis (cinnamon oil) dari permukaan kain hingga terserap kebagian kain yang lebih dalam. Karena untuk proses absorpsi yang baik memerlukan suhu yang sesuai, maka memungkinkan tidak semua komponen minyak kayu manis (cinnamon oil) berdifusi ke dalam kain sehingga pada permukaan kain akan terlihat komponen dari minyak kayu manis (cinnamon oil) tersebut.

Hal tersebut kontradiktif dengan Gambar (c) dan (d) dimana pada kain CVC yang diberikan perlakuan plasma, tampak permukaan kain lebih kasar. Perlakuan plasma menghasilkan kumpulan lepuhan berupa bukit-bukit yang terlihat lebih menonjol dan celah-celah pada permukaan serat serta tampak berpori. Hal ini yang membuat kain CVC lebih mudah menyerap minyak kayu manis (cinnamon oil) akibat dari pembentukan permukaan yang memiliki rongga kecil sehingga molekul minyak kayu manis lebih mudah mengalami absorbsi. Hasil uji SEM menunjukkan bahwa perlakuan plasma telah mengakibatkan terjadinya perubahan morfologi pada permukaan kain CVC. Perubahan morfologi CVC disebabkan oleh reaksi degradasi sehingga terjadi peningkatan derajat kekasaran permukaan (surface roughness) pada kain CVC karena pengikisan akibat perlakuan dengan plasma pijar korona.

Hal ini memperkuat bukti efek plasma secara mikroskopis. Pengaruh dari 
media plasma terhadap besarnya pengelupasan tidak dapat dihitung karena memerlukan metode dan peralatan lainnya. Selain itu luas permukaan kain juga sangat terbatas. Namun demikian hasil ini sudah cukup membuktikan bahwa plasma mampu memberikan efek sesuai dengan yang diinginkan.

\section{Evaluasi kimia}

Uji kimia yang dilakukan adalah analisis gugus fungsi menggunakan Fourier Transform Infrared Spectroscopy (FTIR) untuk mengidentifikasi gugus fungsi kimia yang terdapat pada kain CVC setelah ditanamkan minyak kayu manis (cinnamon oil) baik pada kain dengan perlakuan plasma dan yang tidak diberi perlakuan plasma. Analisis FTIR memiliki tiga fungsi yaitu untuk mengidentifikasi material yang belum diketahui, menentukan kualitas atau konsistensi sampel dan menentukan suatu komponen dalam suatu campuran. Prinsip kerja dari metode analisis ini adalah penyerapan radiasi infra merah dan pelepasannya oleh ikatan-ikatan molekul (Sulistyani, 2017). Hasil dari pengujian FTIR dapat dilihat pada Gambar 2 dan Gambar 3 .

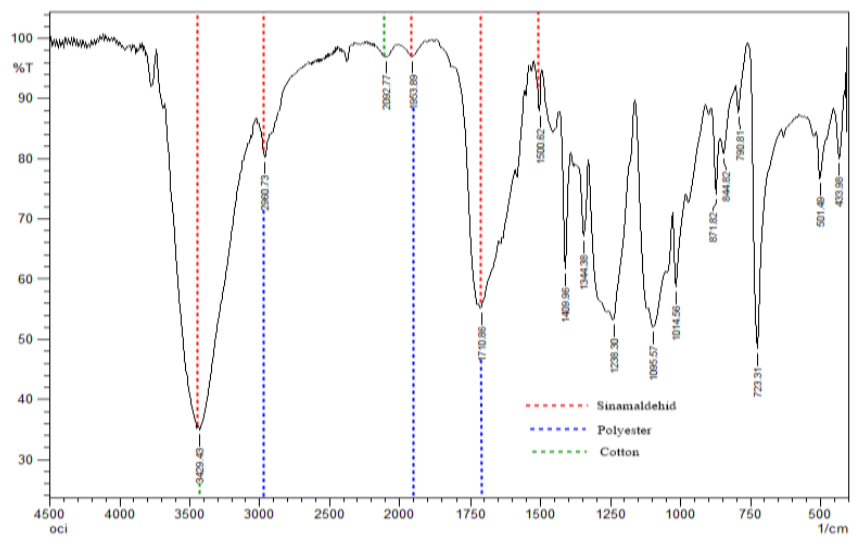

Gambar 2. Uji FTIR pada kain CVC tanpa perlakuan plasma

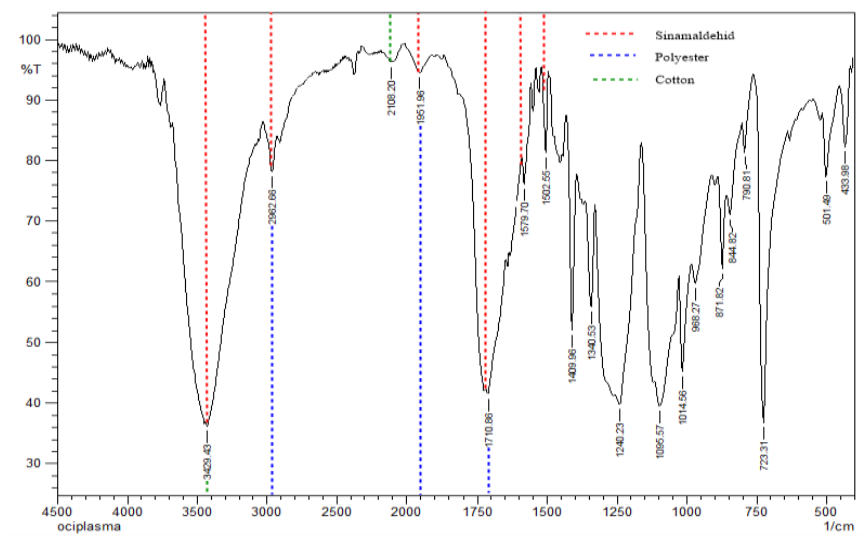

Gambar 3. Uji FTIR pada kain CVC dengan perlakuan plasma

Gugus fungsional yang telah dianalisis berdasarkan hasil spektra uji FTIR pada tekstil CVC dengan perlakuan perendaman dan treatment plasma yang dilanjutkan dengan perendaman memiliki gugus fungsional yang hampir sama. Pada panjang gelombang 3429,43 $\mathrm{cm}^{-1}$ pada keduanya menandakan terdapat gugus $-\mathrm{OH}$, pada panjang gelombang $2960,73 \mathrm{~cm}^{1}$ dan 2962,66 $\mathrm{cm}^{-1}$ menandakan terdapatnya gugus -C-H stretch, pada panjang gelombang $2092,77 \mathrm{~cm}^{-1}$ dan $2108,20 \mathrm{~cm}^{-1}$ menandakan terdapatnya gugus $\mathrm{C} \equiv \mathrm{C}$, pada panjang gelombang 1953,89 dan $1710,86 \mathrm{~cm}^{-1}$ menandakan adanya gugus $\mathrm{C}=\mathrm{O}$, pada panjang gelombang $1579,70 \mathrm{~cm}^{-1} ; 1500,62 \mathrm{~cm}^{-1}$ dan $1502,55 \mathrm{~cm}^{-1}$ menandakan terdapatnya gugus $\mathrm{C}=\mathrm{C}$ aromatik (Adinew, 2014; Marfina et al., 2019; Priastuti et al., 2012; Wen et al., 2016). 
Pada gugus $-\mathrm{OH},-\mathrm{C}-\mathrm{H}$ stretch, $\mathrm{C}=\mathrm{O}$ dan $\mathrm{C}=\mathrm{C}$ aromatik yang terdeteksi diduga merupakan gugus fungsional dari senyawa sinamaldehid yang merupakan marker dari minyak kayu manis. Menurut Marfina et al., (2019) pada penelitiannya, gugus fungsional berdasarkan hasil analisis spektra FTIR sinamaldehid memiliki gugus fungsi $-\mathrm{OH},-\mathrm{C}-\mathrm{H}$ stretch, $\mathrm{C}=\mathrm{O}$ dan $\mathrm{C}=\mathrm{C}$ aromatik. Selain itu menurut Hamid, (2012) minyak atsiri yang aktif sebagai antibakteri pada umumnya mengandung gugus hidroksil $(-\mathrm{OH})$ dan karbonil $(\mathrm{C}=\mathrm{O})$.

Kemudian gugus fungsional $-\mathrm{C}-\mathrm{H}$ stretch dan $\mathrm{C}=\mathrm{O}$ juga merupakan gugus fungsi dari polyester. Terdapatnya persamaan gugus fungsi $-\mathrm{C}-\mathrm{H}$ stretch dan $\mathrm{C}=\mathrm{O}$ pada senyawa sinamaldehid dengan polyester dapat terjadi karena material polyester sendiri terdiri dari matriks polimer yang mempunyai gugus fungsi $-\mathrm{C}-\mathrm{H}$. Selain itu berdasarkan penelitian Bagenda, (2017) menyatakan bahwa material polyester mempunyai gugus fungsi $-\mathrm{C}-\mathrm{H}$, karbonil dan ester sehingga hal tersebutlah yang membuat gugus fungsinya beririsan. Kemudian untuk gugus fungsi $-\mathrm{OH}$ dan $\mathrm{C} \equiv \mathrm{C}$ merupakan gugus fungsi dari katun, dimana gugus fungsi $-\mathrm{OH}$ ini juga beririsan dengan senyawa sinamaldehid. Sehingga identifikasi sampel dari pengujian FTIR ini sesuai dengan literatur bahwa pada kedua perlakuan tersebut mengandung gugus fungsional dari senyawa marker minyak kayu manis yaitu sinamaldehid yang memiliki peran sebagai antibakteri.. Dibuktikan juga bahwa sampel yang diberikan treatment plasma terlebih dahulu memiliki absorbansi yang relatif lebih tinggi dibandingkan dengan tekstil tanpa treatment plasma.

\section{Uji antibakteri}

Pengujian antibakteri ini dilakukan untuk melihat aktivitas antibakteri pada tekstil yang diberi perlakuan perendaman dalam minyak kayu manis dan tekstil yang diberi perlakuan plasma sebelum direndam dengan minyak kayu manis. Selain itu, uji aktivitas antibakteri ini juga dilakukan untuk melihat apakah sampel yang diberi perlakuan plasma memiliki penjerapan yang lebih baik dari pada sampel yang tidak diberi perlakuan plasma. Pengujian ini dilakukan terhadap bakteri Staphylococcus epidermidis. Pada pengujian ini juga dibandingkan dengan produk sediaan anti bau kaki dipasaran dengan merk Actimed. Hasil evaluasi antibakteri yang dinyatakan dengan diameter zona hambat dipaparkan pada Tabel 4 dan Tabel 5.

Tabel 4. Evaluasi antibakteri pada kain CVC tanpa perlakuan plasma

\begin{tabular}{cc}
\hline \hline Sampel & \multicolumn{2}{c}{ Rataan diamater zona hambat $(\mathbf{m m})$} \\
\hline \hline Tanpa pencucian & 9,28 \\
Pencucian ke-6x & 11,40 \\
Pencucian ke-12x & 12,65 \\
Actimed & 11,75 \\
\hline \hline
\end{tabular}

Tabel 5. Evaluasi antibakteri pada kain CVC dengan perlakuan plasma

\begin{tabular}{cc}
\hline Sampel & Rataan diamater zona hambat (mm) \\
\hline \hline Tanpa pencucian & 9,33 \\
Pencucian ke-6x & 14,00 \\
Pencucian ke-12x & 14,15 \\
Actimed & 10,50 \\
\hline \hline
\end{tabular}

Dari hasil penelitian ini aktivitas antibakteri memberikan zona hambat yang lebih kecil daripada produk pembanding (Actimed) yang merupakan sediaan sabun. Karena dalam penelitian ini daya hambat yang dihasilkan lemah maka perlu dipertimbangkan kembali untuk penentuan konsentrasi minyak kayu manis yang lebih tinggi serta durasi atau lamanya waktu 
perendaman minyak kayu manis menjadi lebih lama agar proses penyerapan minyak kayu manis kedalam kain lebih banyak terserap.

Namun dari hasil tersebut juga dapat dilihat bahwa perlakuan dengan plasma menghasilkan peningkatan aktivitas antibakteri meskipun hasilnya nampak tidak terlalu signifikan. Hal ini menandakan bahwa tekstil CVC yang diberikan perlakuan plasma menjerap minyak kayu manis lebih banyak dibandingkan tanpa diberikan perlakuan plasma. Hasil tersebut menunjukkan bahwa tekstil CVC yang diberikan perlakuan plasma memiliki sifat adhesif yang lebih baik dibandingkan dengan tekstil CVC yang tidak diberikan perlakuan plasma, sehingga minyak kayu manis dapat lebih menempel pada tekstil yang diberi perlakuan plasma. Seperti yang sudah dijelaskan sebelumnya bahwa teknologi plasma ini dapat digunakan untuk peningkatan daya serap (wettability), peningkatan adhesi, sterilisasi, sifat daya tarik kimia (chemical affinity) dan biocompatibility.

\section{Uji Stabilitas Tekstil Medis}

Evaluasi daripada pengujian stabilitas terhadap tekstil yang sudah ditanamkan minyak kayu manis bertujuan untuk melihat aktivitas antibakteri pada sampel yang sudah mengalami pencucian sebanyak 12 kali. Hasil pengujian sampel terhadap Staphylococcus epidermidis dapat dilihat pada Tabel 4 dan Tabel 5.

Dari hasil uji tersebut dapat dilihat bahwa daya hambat tanpa pencucian pada sampel yang diberi perlakuan plasma maupun tidak menuju pencucian ke-6 dan ke-12 terus meningkat. Meningkatnya zona hambat ini diduga karena bantuan mekanik pada saat pencucian yang memiliki sumbangsih terhadap lepasnya zat, dalam hal ini minyak kayu manis yang terjerap dalam tekstil. Selain itu pencucian menggunakan detergen memungkinkan juga menjadi salah satu faktor meningkatnya daya hambat pada sampel dengan pencucian. Detergen juga memiliki sumbangsih untuk membantu mengeluarkan minyak kayu manis ke permukaan tekstil.

Detergen mengandung surfaktan yang diketahui memiliki struktur molekul amphipatik yang terdiri dari gugus hidrofilik dan gugus hidrofobik. Tekstil CVC yang diberikan perlakuan plasma permukaannya berongga sehingga kemungkinan minyak kayu manis masuk kedalam material tekstil CVC dan terjerap didalam jerapan berukuran nanometer. Mengingat setelah perlakuan plasma sifat adhesi dari material tekstil akan meningkat. Surfaktan memiliki dua gugus yaitu gugus hidrofobik yang dapat mengikat minyak kayu manis hingga terbentuk Critical Micelle Concentration (CMC). Sedangkan gugus hidrofilik akan mengikat air pada saat proses pembilasan menggunakan air (Suryani, 2005).

Ketika proses pembilasan, minyak kayu manis dapat naik ke permukaan tekstil setelah terjerap dalam material tekstil. Hal tersebut yang dapat mengakibatkan daya hambat pada pencucian ke-6 dan ke-12 naik. Hal ini juga terjadi pada sampel yang tidak diberikan perlakuan plasma. Namun dari hasil tersebut dapat dilihat bahwa daya hambat pada tekstil perlakuan plasma relatif lebih tinggi daripada material tekstil tanpa perlakuan plasma.

\section{Kesimpulan}

Berdasarkan penelitian mengenai penerapan metode plasma dalam kaos kaki mengandung minyak kayu manis (cinnamon oil) menunjukkan bahwa perlakuan plasma merupakan teknik yang lebih efektif dibandingkan hanya dilakukan proses perendaman saja dilihat dari uji evaluasi berupa uji kimia, fisika, uji efektivitas antibakteri serta uji stabilitas.

\section{Acknowledge}

Alhamdulillah, segala puji dan syukur penulis panjatkan kehadirat Allah SWT karena hasil penelitian ini telah selesai disusun. Penulis pun menyadari jika dalam penyusunan ini masih mempunyai kekurangan, namun penulis berharap hasil penelitian ini tetap akan memberikan manfaat bagi pembaca.

\section{Daftar Pustaka}

[1] Achmad, KH Sitohang. (2015). Rancang Bangun Prototip Mesin Plasma Tekstil Lucutan Korona Pada Tekanan Atmosfir Skala Laboratorium. Arena Tekstil Vol. 30 No. 1, Juni 
2015: 25-36.

[2] Adinew, B. (2014). GC-MS and FT-IR Analysis of Constituents of Essential Oil from Cinnamon Bark Growing in South-West of Ethiopia. IJHM, 1(6), 22-31.

[3] Amril, H. (2015). Teknologi Plasma untuk Pengolahan Air. Jurusan Teknik Kimia, Institut Teknologi Bandung: Bandung.

[4] Ara, K., Hama, M., Akiba, S., Koike, K., Okisaka, K., Hagura, T., Kamiya T., Tomita, F. (2006). Foot Odor due to Microbial Metabolism and its Control. Can. J. Microbiol., 52, 357-364.

[5] Chang, J.S. (1991) Corona Discharge Processes. IEEE Transaction on Plasma Science Vol. 19.

[6] Champman, B. (1990) Glow Discharge Processes, John Willey \& Sons: New York.

[7] Guenther, E. (2006). Minyak Atsiri. Jilid I. Diterjemahkan oleh S. Ketaren. UI Press: Jakarta.

[8] Gupta C., Garg, A. P., Uniyal, R. S., Kumari, A. (2008). Comparative Analysis of The Antimicrobial activity of Cinnamon Oil and Cinnamon Extract on Somefoodborne microbes. African Journal of Microbiology Research, 2 (9), 247-251.

[9] Harun, N. (2010). Karakteristik Minyak Kayu Manis (Cinnamomum burmanii blume) Berdasarkan Letak Kulit pada Batang dan Ukuran Bahan Pada Proses Penyulingan. SAGU, Vol. 9, No. 2.

[10] Inna, M., Atmania, N., Primasari, S. (2010). Potential Use of Cinnamomum burmanii Essential Oil-based Chewing Gum as Oral Antibiofilm Agent. Journal of Densitry Indonesia, $10^{\text {th }}$, Vol. 17, No. 3.

[11] Kobayashi, S. (1990). Relationship between an offensive smell given off from human foot and Staphylococcus epidermidis. Nihon Saikingaku Zasshi,45 (4), 797-800.

[12] Lukes, P dan Locke B. R (2005). Plasmachemical oxidation processes in a hybrid gasliquid electrical discharge reactor J. Phys. D:Appl. Phys. 38 4074-81.

[13] Marfina, Apriza., dkk. (2019). Sintesis Nanopartikel Emas dengan Bioreduktor Minyak Atsiri Kayu Manis (Cinnamomum burmanii). Indonesian Journal of Chemical Science.

[14] Mutia, Theresia. (2009). Peranan Serat Alam untuk Bahan Baku Tekstil Medis Pembalut Luka (Wound Dressing). Arena Tekstil, Vol.24, No.2 halaman 81.

[15] Priastuti, N., Ngadiwiyana dan Ismiyarta. (2012). Sintesis Amil Sinamata dari Sinamaldehid dan Uji Aktivitas sebagai Bahan Aktif Tabir Surya. Jurnal Kimia Sains dan Aplikasi, IX (3), 81-83.

[16] Putra, Valentinus Galih Vidia dan Andrian Wijayono. (2019). Suatu Studi Awal Modifikasi Sifat Pembasahan pada Permukaan Kain Tekstil Polyester 100\% Menggunakan Teknologi Plasma Pijar Korona. Prosiding Seminar Nasional Fisika. Vol. VIII.

[17] Tiran, Fitri Apriliyani dan Christofori. (2014). Aktivitas Antibakteri Lotion Minyak Kayu Manis Terhadap Staphylococcus epidermidis Penyebab Bau Kaki. Jurnal Farmasi Sains dan Komunitas, Vol.11,No.2 halaman 72.

[18] Robbers, J. E., Marylin K. S., Varro E. T. (1996). Pharmacobiotechnology, 95-96, William $\&$ Wilkins Baltimore.

[19] Wen, P., Zhu, D. H., Wu, H., Zong, M. H., Jing, Y.R., \& Han, S. Y. (2016). Encapsulation of Cinnamon Essential Oil in Electrospun Nanofibrous Film for Active Food Packaging. Food Control, 59, 366-376. 